\title{
Effect of Pentoxifylline on Cytokine- and Eicosanoid-Induced Acute Pulmonary Hypertension in Piglets
}

\author{
WILLIAM E. TRUOG, RONALD L. GIBSON, JR., WILLIAM R. HENDERSON, JR., \\ GREGORY J. REDDING, AND THOMAS A. STANDAERT \\ Department of Pediatrics, Division of Neonatal and Respiratory Diseases [W.E.T., R.L.G., G.J.R., T.A.S.J, and \\ Department of Medicine, Division of Allergy and Infectious Diseases [W.R.H.], University of Washington School \\ of Medicine, Seattle, Washington 98195
}

\begin{abstract}
The methylxanthine derivative pentoxifylline (PTF) demonstrates vasodilatory properties in vivo. We tested the hypothesis that PTF infusion would blunt or inhibit tumor necrosis factor- $\alpha\left(\mathrm{TNF}_{\alpha}\right)$-induced and U46,619-induced increases in mean pulmonary artery pressure and pulmonary vascular resistance (PVR) in the neonatal piglet and would do so by altering production of eicosanoid vasoactive mediators. Anesthetized, paralyzed piglets (age 10-29 d) were randomized and treated with a 30 -min infusion of $\mathrm{TNF}_{\alpha}$ alone ( $n=13$ animals), with a combination of $\mathrm{TNF}_{\alpha}$ plus pretreatment and continuous infusion with PTF $(n=6)$, or with a combination of U46,619 for 30 min plus pretreatment and continuous infusion of PTF $(n=5)$. There was no difference in pulmonary or systemic hemodynamic indices between the three groups at baseline. PVR was significantly elevated at $15 \mathrm{~min}$ and at $2 \mathrm{~h}$ in the $\mathrm{TNF}_{\alpha}$-only group. The $\mathrm{TNF}_{\alpha-}$ induced rise in mean pulmonary artery pressure and PVR was inhibited by the PTF until $2 \mathrm{~h}$, by which time PVR was elevated above baseline and was comparable to the value found in animals treated with only $\mathrm{TNF}_{\alpha}$. PTF produced no inhibition in the U46,619-induced elevation of PVR during the 30-min simultaneous treatment. In the

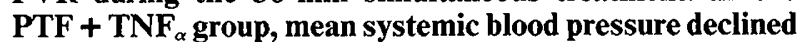
to $50 \%$ of baseline value $(p<0.02)$ by $2 \mathrm{~h}$ of age. No significant decline was noted in mean systemic arterial pressure of the $\mathrm{TNF}_{\alpha}$-only or the U46,619-treated group. Plasma 6-keto-prostaglandin $F_{1 \alpha}$ increased above baseline values by $2 \mathrm{~h}$ only in the PTF $+\mathrm{TNF}_{\alpha}$-treated group $(p<$ $0.02)$; no significant change from baseline in thromboxane $B_{2}$ levels was found in any experimental group. We conclude that treatment with PTF transiently inhibited the $\mathrm{TNF}_{\alpha}$-induced elevation in mean pulmonary artery pressure and PVR but was associated also with significant systemic hypotension. PTF failed to counteract elevated PVR produced by the thromboxane mimetic, U46,619. (Pediatr Res 31: 163-169, 1992)
\end{abstract}

\section{Abbreviations}

PTF, pentoxifylline

$\mathrm{TNF}_{\alpha}$, tumor necrosis factor- $\alpha$

rhTNF $_{\alpha}$, recombinant human tumor necrosis factor- $\alpha$ PVR, pulmonary vascular resistance

Ppa, mean pulmonary artery pressure

Received December 17, 1990; accepted September 17, 1991.

Correspondence: William E. Truog, M.D., Department of Pediatrics RD-20, Division of Neonatal and Respiratory Diseases, University of Washington School of Medicine, Seattle, WA 98195.

Supported in part by PHS Grants RR-00166, HL-01653, HL-39157, HL-30542, and an RJR Nabisco Pulmonary Research Scholar Award (R.L.G.).
Òp, pulmonary blood flow

6-keto-PGF ${ }_{1 \alpha}$, 6-keto prostaglandin $\mathrm{F}_{1 \alpha}$

$\mathbf{P G I}_{2}$, prostaglandin $\mathrm{I}_{2}$

TX, thromboxane

GBS, group B streptococcus

$\dot{\mathrm{V}}_{\mathrm{A}} / \dot{\mathrm{Q}}$, ventilation-perfusion ratio

$\mathrm{P}_{\mathrm{v}} \mathrm{O}_{2}$, mixed venous partial pressure of oxygen

Pulmonary hypertension induced by a variety of possible mechanisms characterizes or complicates many neonatal respiratory disorders $(1,2)$. For example, phospholipid vasoactive mediators may induce or exacerbate pulmonary hypertension in the clinical syndrome of persistent pulmonary hypertension of the newborn $(3,4)$. Both membrane-derived eicosanoids and polypeptide cytokines can produce acute increases in Ppa in neonatal experimental animals $(5,6)$. However, at present, there is no comprehensive understanding of how combinations of various classes of vasoactive mediators interact to initiate or sustain elevations in PVR. It is also unclear how the interaction of vasoactive substances interferes with pulmonary gas exchange during induced pulmonary hypertension.

We (7) and others (8) have shown that bacterial infusioninduced release of $\mathrm{TXA}_{2}$ (measured by its metabolite $\mathrm{TXB}_{2}$ ) produced both immediate pulmonary hypertension and interference with $\dot{\mathrm{V}}_{\mathrm{A}} / \dot{\mathrm{Q}}$ matching. The TX mimetic, U46,619, also produces immediate increases in PVR in neonatal animals (5, 9). This model system can serve to test the specific effects of putative pulmonary vasodilator agents in a neonatal animal.

The polypeptide cytokine $\mathrm{TNF}_{\alpha}$ induces multiple pulmonary pathophysiologic changes in adult animal models (10). We have shown previously that an acute increase in PVR in neonatal piglets can be induced by an i.v. infusion of $\operatorname{rhTNF}_{\alpha}(6)$. The elevated Ppa was transiently inhibited by pretreatment with the putative TX synthase inhibitor, dazmegrel. We have also recently demonstrated elevated plasma levels of $\mathrm{TNF}_{\alpha}$ beginning after 2 $h$ of i.v. bacterial infusion, suggesting that this substance may participate in maintaining elevated PVR during later phases of neonatal sepsis (11).

The methylxanthine derivative PTF has been shown in vitro to inhibit $\mathrm{TNF}_{\alpha}$-induced changes in neutrophil adherence to endothelial cells $(12,13)$ and has been shown in vivo to protect against endotoxin-induced pulmonary vascular injury in both dogs (14) and guinea pigs (15). Because endotoxin induces $T_{N} F_{\alpha}$ production, the beneficial effects of PTF may have occurred by inhibition of either $\mathrm{TNF}_{\alpha}$ synthesis, release, or activity (15). In the neonatal piglet model, a co-infusion of PTF with a $4 \mathrm{~h}$ infusion of GBS produced a decrease in plasma $\mathrm{TNF}_{\alpha}$ levels to 
$20 \%$ of that found in GBS-infused animals without PTF treatment by $4 \mathrm{~h}$ (11). However, there was no difference in plasma $\mathrm{TXB}_{2}$ by $4 \mathrm{~h}$ and only modest reduction in the PVR of the GBS + PTF animals compared with the GBS only animals. These results, combined with our previous finding of transient TX synthase inhibition of $\mathrm{TNF}_{\alpha}$ effects (6), raise questions about whether PTF can act as a competitive inhibitor of TX and whether PTF can alter $\mathrm{TNF}_{\alpha}$-induced pulmonary vasoconstriction once the cytokine is released into the pulmonary circulation.

To study possible mechanisms of action of PTF, we tested the effects of PTF infusion in neonatal piglets simultaneously infused with the TX mimetic U46,619 and in separate animals infused with $\mathrm{rhTNF}_{\alpha}$. We investigated the effects of these infusions on pulmonary and systemic hemodynamic indices, respiratory gas exchange, and arachidonate production.

\section{MATERIALS AND METHODS}

Animal preparation. Healthy mixed-strain piglets aged 10-29 $\mathrm{d}$ were prepared as previously described (6). Each animal was anesthetized with pentobarbital, paralyzed with pancuronium, and mechanically ventilated via a tracheostomy. The animals had pulmonary arterial, systemic arterial, and peripheral venous catheters inserted. Animals were maintained at a core temperature of $38.0-38.5^{\circ} \mathrm{C}$ using overhead heating lamps. Animals received inflations of twice normal tidal volume before each data sampling time to minimize atelectasis. Ten $\mathrm{mL} / \mathrm{kg}$ of $0.9 \%$ saline were administered to each animal after onset of anesthesia before initiation of the experimental protocol to assure adequate intravascular volume.

$T N F_{\alpha}$ preparation. rhTNF$_{\alpha}$, derived from Escherichia coli, was kindly supplied as a gift from Knoll Pharmaceutical Company (Whippany, NJ). The material was supplied as a lyophilized powder; each glass vial contained $0.98 \mathrm{mg} \mathrm{rhTNF}_{\alpha}$ (sp act $9.8 \times$ $\left.10^{6} \mathrm{U} / \mathrm{mg}\right)$. The vials were kept frozen $\left(-70^{\circ} \mathrm{C}\right)$ until the day of each experiment. The material was reconstituted to $100 \mu \mathrm{g} / \mathrm{mL}$ with sterile water containing $0.5 \mathrm{~g} / 100 \mathrm{~mL}$ human serum albumin. Only glass syringes were used for reconstitution and administration, because rhTNF$F_{\alpha}$ adheres less to glass than to plastic. Six of the 13 animals receiving $\mathrm{TNF}_{\alpha}$ alone received $\mathrm{TNF}_{\alpha}$ from one batch; the other seven animals in the $\mathrm{TNF}_{\alpha}$ alone group and the six animals receiving $\mathrm{TNF}_{\alpha}$ and PTF had their $\mathrm{TNF}_{\alpha}$ obtained from a separately supplied batch. Significant contamination of the $\mathrm{TNF}_{\alpha}$ preparation with endotoxin was ruled out as previously described (6).

PTF preparation. Intravenous PTF (Trental; Hoechst-Roussel Pharmaceuticals, Somerville, NJ) was prepared fresh each experimental day. The material was dissolved in sterile normal saline and administered by continuous infusion using a glass syringe.

U46,619 preparation. The TX mimetic, U46,619, which is 9,11,dideoxy-1 1a,9a epoxymethano-prostaglandin $F_{2 a}$ (Upjohn Pharmaceutical Company, Kalamazoo, MI), was supplied as 1 $\mathrm{mg} / \mathrm{mL}$ in methylacetate. Aliquots of $100 \mu \mathrm{g}$ were removed, dried, and resuspended in $95 \%$ ethanol and stored at $-20^{\circ} \mathrm{C}$. Before each experiment, an aliquot was removed, thawed, and combined in normal saline. This solution was administered at a dose of $0.15 \mu \mathrm{g} / \mathrm{kg} / \mathrm{min}$.

Arachidonic acid metabolite assay. RIA was performed on arterial plasma for measurement of $\mathrm{TXB}_{2}$, the nonenzymatically derived breakdown product of $\mathrm{TXA}_{\alpha}$, and 6-keto-PGF ${ }_{1 \alpha}$, the stable metabolite of $\mathrm{PGI}_{2}$. The details of the methodology used in our laboratory have been previously published $(6,16)$. At each sampling time, a 1.8-mL sample of arterial blood was drawn into $0.2 \mathrm{~mL}$ freshly prepared cold inhibitor solution containing indomethacin and sodium EDTA, previously drawn into prechilled syringes. Samples were kept in an ice bath until centrifugation at $15000 \mathrm{rpm} \times 15 \mathrm{~min}$ at $4^{\circ} \mathrm{C}$. Plasma was decanted, frozen, and stored at $-70^{\circ} \mathrm{C}$ until RIA was performed. Samples were analyzed in duplicate and the two values averaged.

No matrix effects due to protein present in control piglet plasma samples were found when standard curves run with eicosanoid-free piglet plasma prepared by charcoal stripping were compared with curves generated from samples not treated with charcoal. The antibodies against $\mathrm{TXB}_{2}$ and 6-keto-PGF ${ }_{1 \alpha}$ were produced in our laboratory (W.R.H.) and have sensitivities of 1 $\mathrm{pg} / 0.1-\mathrm{mL}$ sample at a dilution of $1: 100000$ and $10 \mathrm{pg} / 0.1-\mathrm{mL}$ sample at a dilution of $1: 6000$, respectively $(17,18)$. Values below the level of sensitivity were considered to be equal to the sensitivity limit of the assay.

Experimental protocol. The methods and experimental protocols for these studies were approved by the Animal Care Committee of the University of Washington.

Animals were randomized into three groups. Group 1 animals $(n=6)$ received a total dose of $200 \mu \mathrm{g} / \mathrm{kg} \mathrm{TNF} \alpha\left(9.8 \times 10^{6} \mathrm{U} /\right.$ $\mathrm{mg}$ ) infused i.v. at a constant rate into a peripheral vein over 30 min. They also received a bolus of $20 \mathrm{mg} / \mathrm{kg}$ PTF before the $\mathrm{TNF}_{\alpha}$ infusion followed immediately by a continuous infusion of $20 \mathrm{mg} / \mathrm{kg} / \mathrm{h}$ PTF for the $2 \mathrm{~h}$ of the experimental protocol. Thirteen animals (group 2) received $\mathrm{TNF}_{\alpha}$ at the same dose at the same infusion rates as the animals in group 1 . They also received $0.9 \%$ saline at the same infusion rate as the PTF infusion into the $\mathrm{TNF}_{\alpha}+$ PTF-treated animals. Group 3 animals received PTF in the same dosage as group 1 and also received a 30-min infusion of $U 46,619(0.15 \mu \mathrm{g} / \mathrm{kg} / \mathrm{min})$ beginning just after the PTF bolus. After the 2-h PTF infusion was completed and a new baseline was established, a repeat 30-min infusion of U46,619 was administered to this group of animals to assess the pulmonary hypertensive response to $\mathrm{U} 46,619$ without concomitant infusion of PTF.

Pulmonary and systemic pressures were measured continuously in all animals. Measurements of Q $p$, hemodynamic indices, respiratory gas exchange, and arachidonic acid metabolite levels were made at baseline, just before onset of either the $\mathrm{TNF}_{\alpha}$, $\mathrm{U} 46,619$, or $\mathrm{TNF}_{\alpha}$ plus PTF infusion, and at 15 (hemodynamics only), 30, 60, and 120 min. Qp was measured at least in triplicate using the thermodilution technique (Edwards 9520A cardiac output computer; Edwards Laboratories, Santa Ana, CA), and the results were averaged.

Two additional animals received a bolus of $20 \mathrm{mg} / \mathrm{kg}$ and a continuous infusion of $40 \mathrm{mg} / \mathrm{kg} / \mathrm{h}$ of PTF during TNF $\alpha$ infusion to determine the effects of a higher dosage. Because there was no effect on PVR different from that found at the lower dose and a further decline in mean systemic arterial pressure to $4 \mathrm{kPa}(30$ $\mathrm{mm} \mathrm{Hg}$ ), this higher dosage was not used in the main study. We have previously established that the use of anesthesia in similarly instrumented piglets for $6 \mathrm{~h}$ of study causes no deterioration in gas exchange or hemodynamic indices (19). We have also previously shown that animals of similar age and mean weight as those in the present study treated with the same dose of PTF for $4 \mathrm{~h}$ demonstrated no measurable effects (11).

Statistical analysis. One-way analysis of variance was carried out on the mean data for each group of animals. If intragroup differences were suggested, a paired $t$ test was then carried out to demonstrate significant differences compared with baseline in each group. Intergroup comparisons were made using the unpaired $t$ test. Significance was assumed with a $p$ value $<0.05$. Data are presented as mean $\pm \mathrm{SD}$.

\section{RESULTS}

Baseline comparisons. The three groups of animals were well matched by postnatal age and weight at the time of study (Table 1). There was no difference in mean baseline values for Ppa and PVR or mean response between the groups of $\mathrm{TNF}_{\alpha}$-only animals that had received the $\mathrm{TNF}_{\alpha}$ from the two different batches. Data from these two subgroups were therefore combined. There was no correlation between animal age and pulmonary pressor response to $\mathrm{TNF}_{\alpha}$ within the age range examined (data not shown).

Pulmonary hemodynamic measurements. Infusion of $\mathrm{TNF}_{\alpha}$ and U46,619 induced an increase in Ppa by $15 \mathrm{~min}$. This increase 
Table 1. Baseline data (mean $\pm S D)$

\begin{tabular}{lccc}
\hline & $\begin{array}{c}\mathrm{TNF}_{\alpha} \text { group } \\
(n=13)\end{array}$ & $\begin{array}{c}\mathrm{TNF}_{\alpha}+\mathrm{PTF} \\
\text { group } \\
(n=6)\end{array}$ & $\begin{array}{c}\text { U46,619 + PTF } \\
\text { group }(n=5)\end{array}$ \\
\hline Study age (d) & $17 \pm 7$ & $16 \pm 3$ & $12 \pm 2$ \\
(Range) & $(10-29)$ & $(12-19)$ & $(10-16)$ \\
Study weight $(\mathrm{kg})$ & $4.1 \pm 0.8$ & $3.7 \pm 1.2$ & $3.2 \pm 0.2$ \\
(Range) & $(2.2-6.1)$ & $(2.6-5.8)$ & $(2.9-3.5)$ \\
\hline
\end{tabular}

did not occur in the $\mathrm{TNF}_{\alpha}$-treated animals pretreated with PTF, but did occur in the U46,619-treated animals (Fig. 1). The inhibition in Ppa increase lasted until $2 \mathrm{~h}$ after onset of infusion in the $\mathrm{TNF}_{\alpha}+\mathrm{PTF}$ group (Fig. 1). No group of animals demonstrated a significant decline in mean $Q \mathrm{p}$ compared to baseline for each group (Fig. 2). There was no difference in mean Qp between the groups at any experimental measurement point (Fig. 2). Calculated PVR was maintained at baseline level in the $\mathrm{TNF}_{\alpha}$ + PTF-treated animals until $2 \mathrm{~h}$, when it was significantly elevated above baseline and comparable to that found in the animals treated only with $\mathrm{TNF}_{\alpha}$ (Fig. 3). The $\mathrm{TNF}_{\alpha}$-only treated animals demonstrated significant elevation in PVR compared to baseline and the $\mathrm{TNF}_{\alpha}+$ PTF group at $15 \mathrm{~min}$ and at $2 \mathrm{~h}$ compared to baseline after onset of infusion. The PTF had no inhibitory effect on the U46,619-induced increase in PVR at 15 or $30 \mathrm{~min}$. The increase in PVR was the same at $30 \mathrm{~min}$ of infusion with U46,619 with or without concomitant PTF infusion $(14.5 \pm 2.4$ versus $13.7 \pm 2.9 \mathrm{kPa} / \mathrm{L} / \mathrm{min} / \mathrm{kg}$ or $109 \pm 18$ versus $103 \pm 28 \mathrm{~mm} \mathrm{Hg} / \mathrm{L} / \mathrm{min} / \mathrm{kg}$ ).

Effect on systemic hemodynamics. Mean systemic blood pressure (Fig. 4) demonstrated a statistically insignificant decline from baseline in the $\mathrm{TNF}_{\alpha}$-only group over the 2-h experimental period. However, systemic blood pressure in the $\mathrm{TNF}_{\alpha}+\mathrm{PTF}-$ treated group declined significantly compared to baseline by $2 \mathrm{~h}$. Mean systemic blood pressure showed no significant changes over time in the U46,619 + PTF-treated group.

Effect on pulmonary gas exchange. Each group of animals demonstrated no significant decline from baseline for arterial $\mathrm{PO}_{2}$ and $\mathrm{PvO}_{2}$ at each experimental point, with no intergroup difference between mean values (Table 2). There was an insignificant decline in arterial $\mathrm{PO}_{2}$ in all three groups of animals by the end of $2 \mathrm{~h}$. Arterial $\mathrm{PCO}_{2}$ was not different by design at any experimental time point in any of the three groups. The $\mathrm{TNF}_{\alpha^{-}}$ only animals showed a decline in $\mathrm{P}_{\mathrm{V}} \mathrm{O}_{2}$ by $2 \mathrm{~h}$; no decline in $\mathrm{PVO}_{2}$ was noted in the $\mathrm{TNF}_{\alpha}+$ PTF or the U46,619 + PTF group of animals. Arterial $\mathrm{pH}$ did not change in any group (data not shown).

Arachidonic acid metabolite levels. Data for serial measurements of $\mathrm{TXB}_{2}$ and for 6-keto-PGF ${ }_{1 \alpha}$ are shown in Figures 5 and 6. Administration of $\mathrm{TNF}_{\alpha}$-only, $\mathrm{TNF}_{\alpha}+\mathrm{PTF}$, or U46,619+ PTF caused no significant change from baseline in $\mathrm{TXB}_{2}$ levels at any experimental time point. Analysis of the 6-keto-PGF 1 a data showed that $\mathrm{TNF}_{\alpha}$ alone and U46,619 + PTF produced no statistically significant increase compared to baseline measurement, comparable to our previous findings with PTF infusion alone (11). However, there was a progressive rise in 6-keto-PGF $F_{1 a}$ levels in the $\mathrm{TNF}_{\alpha}+$ PTF-treated animals, such that mean levels were 12 -fold higher than baseline by $2 \mathrm{~h}(p<0.05)$ and 15 -fold higher compared to the mean level obtained at the same time in the $\mathrm{TNF}_{\alpha}$-only treated animals $(p<0.02)$.

\section{DISCUSSION}

The present results demonstrated that the methylxanthine derivative PTF can transiently inhibit the $\mathrm{TNF}_{\alpha}$-induced elevation in Ppa and PVR in neonatal animals. However, by $1.5 \mathrm{~h}$ after the end of the $\mathrm{TNF}_{\alpha}$ infusion, the $\mathrm{TNF}_{\alpha}+\mathrm{PTF}$ animals manifested the same increase in PVR despite continuous infusion of PTF as that found in the animals that received a 30 -min infusion of $\mathrm{TNF}_{\alpha}$ alone, the latter group having an elevated PVR after the end of the TNF $\mathrm{TN}_{\alpha}$ infusion. The increased PVR in both groups of animals at $2 \mathrm{~h}$ occurred because of a significant increase in Ppa compared to baseline for each group. In contrast, PTF infusion produced no inhibition of the U46,619-induced increase in PVR at 15 or 30 min (Figs. 1-3). Intravenous infusion with PTF and $\mathrm{TNF}_{\alpha}$ was associated with a significant rise in 6-ketoPGF $_{1 \alpha}$ levels by $1 \mathrm{~h}$ after onset of infusion, a finding particularly marked by $2 \mathrm{~h}$. The acute inhibition of elevated PVR at $15 \mathrm{~min}$ was not due to inhibition of $\mathrm{TXB}_{2}$, inasmuch as there was no elevation of $\mathrm{TXB}_{2}$ in either group. Use of PTF with $\mathrm{TNF}_{\alpha}$ was also associated with a significant decline in systemic arterial pressure by $2 \mathrm{~h}$ after onset of infusion.

When administered acutely, $\mathrm{TNF}_{\alpha}$ induces many characteristics of septic shock, including derangements in cardiovascular, metabolic, hematologic, and inflammatory homeostasis $(20,21)$. However, it is unlikely that infusion of a single vasoactive

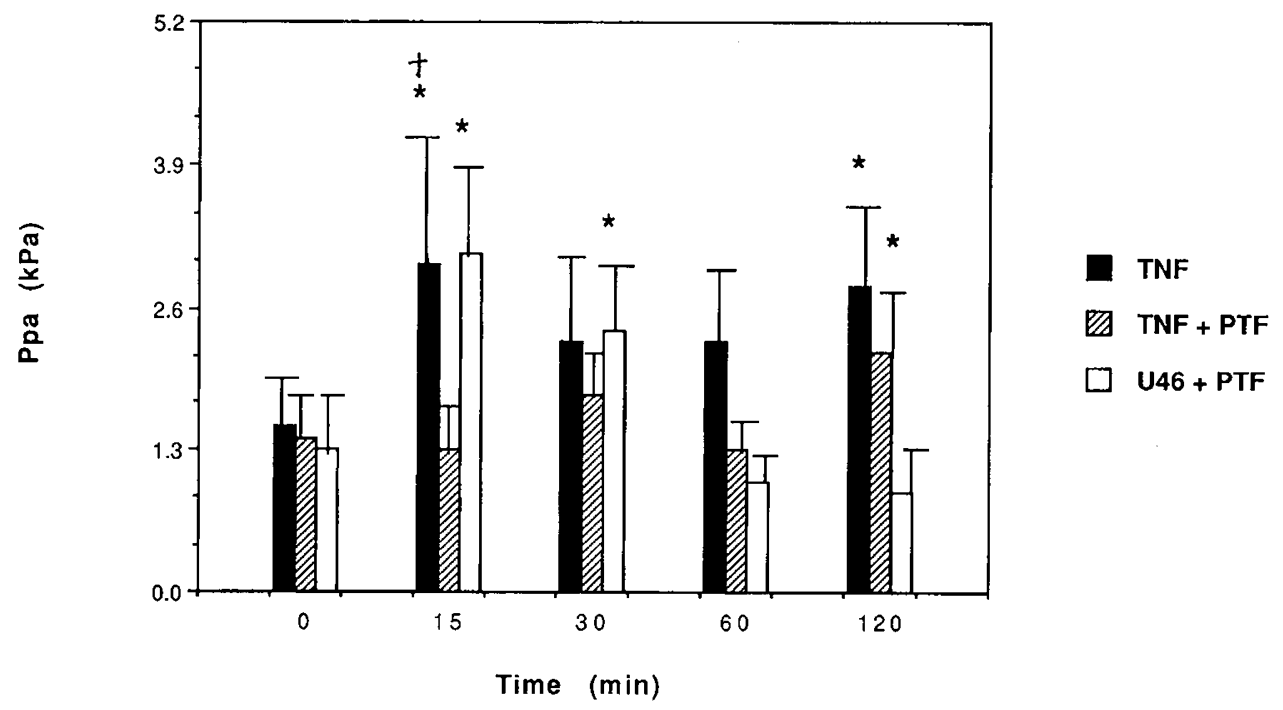

Fig. 1. Ppa is plotted for the three groups against experimental time points. Ppa was elevated compared to baseline at 15 and 120 min in the group receiving $\mathrm{TNF}_{\alpha}$ only and at $15 \mathrm{~min} \mathrm{Ppa}$ was higher in the $\mathrm{TNF}_{\alpha}$ group compared to the TNF + PTF group. At $2 \mathrm{~h}$ the Ppa in the TNF + PTF group was elevated compared to baseline. The U46,619 group showed an increase in Ppa at 15 and 30 min compared to baseline. TNF ${ }_{\alpha}$ and $\mathrm{U} 46,619$ were infused continuously through the 30 -min data point collection; PTF was infused continuously through the 2 -h time point. $1 \mathrm{~mm} \mathrm{Hg}$ $=0.13 \mathrm{kPa} .{ }^{*} p<0.02 v s$ baseline; $\dagger, p<0.02 v s \mathrm{TNF}_{\alpha}+$ PTF group. 


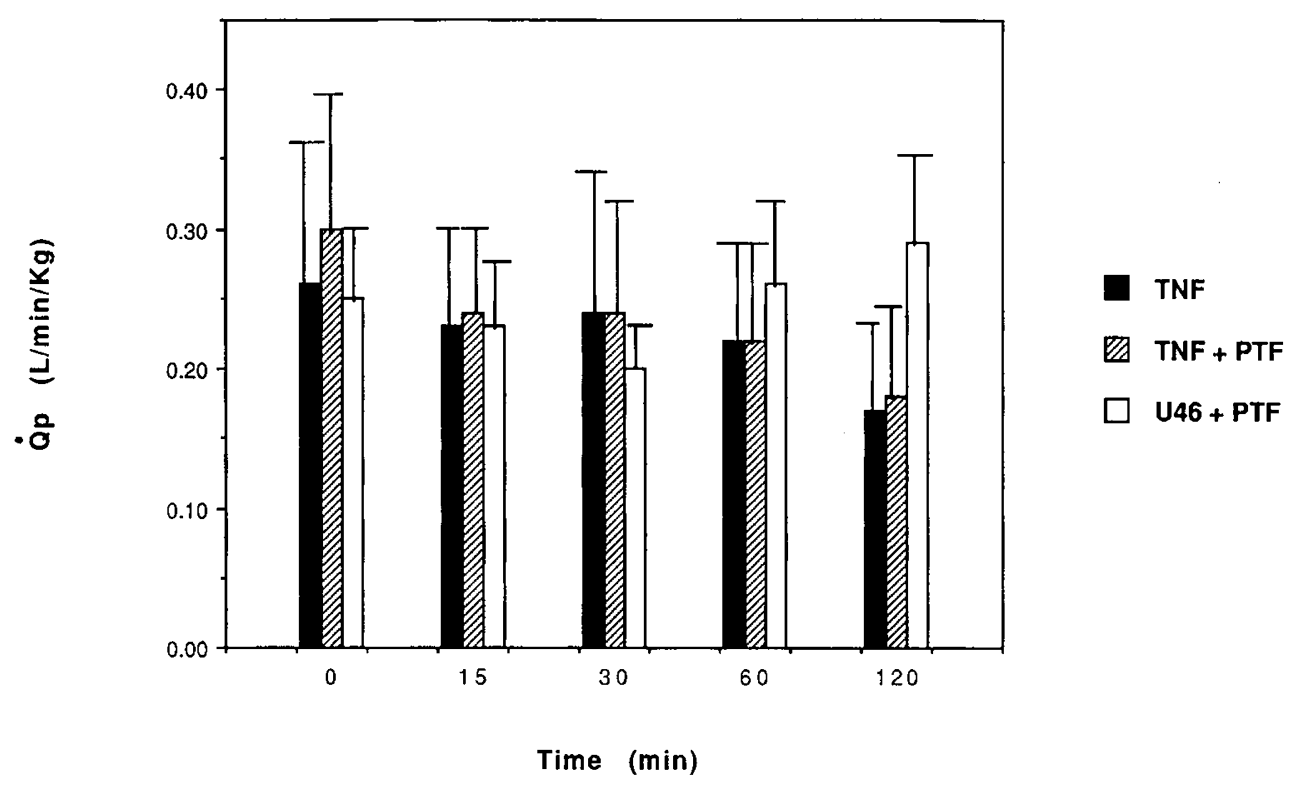

Fig. 2. Q̀p expressed as $\mathrm{L} / \mathrm{min} / \mathrm{kg}$ is plotted against experimental time points. All groups showed a statistically nonsignificant decline by $2 \mathrm{~h}$ compared to baseline.

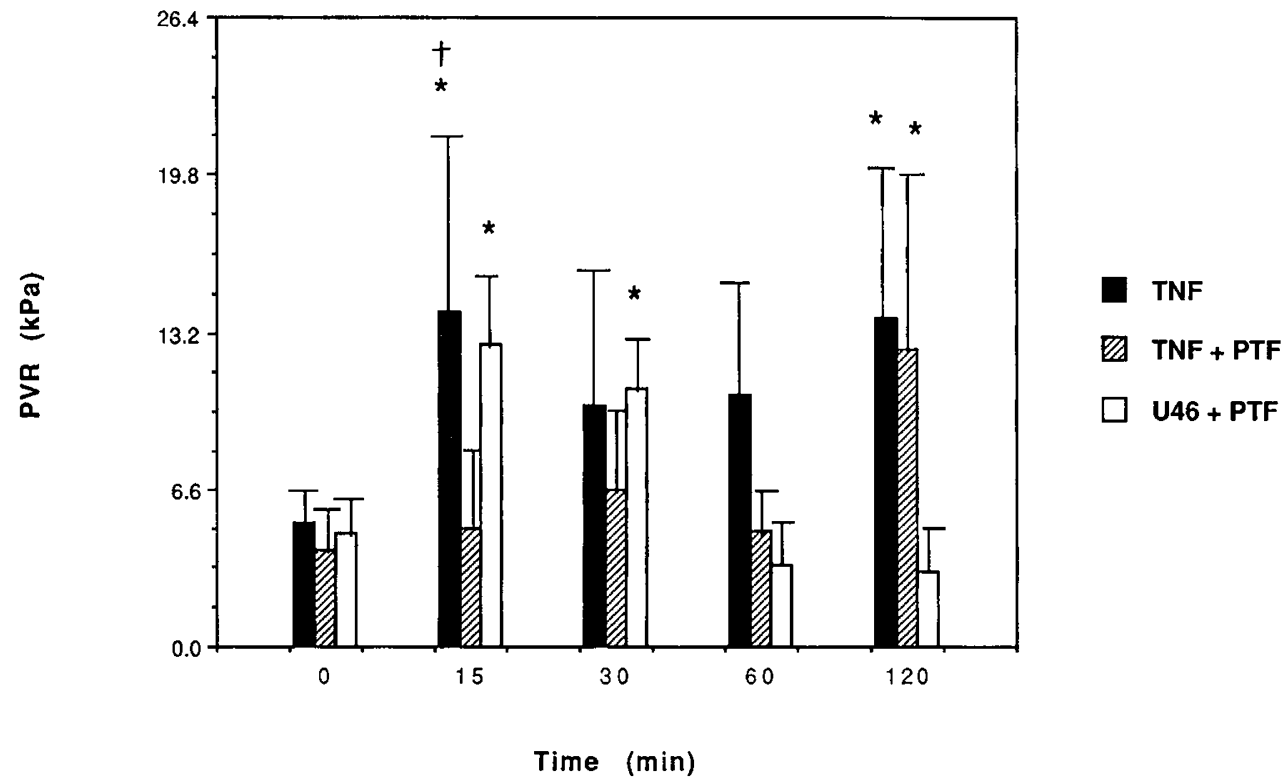

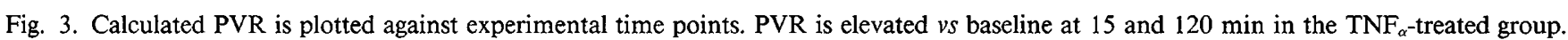
The U46,619 + PTF group showed increased PVR at $15 \mathrm{~min}$ and 30 min only compared to baseline. By $2 \mathrm{~h}$, PVR is also elevated $v s$ baseline in the $\mathrm{TNF}_{\alpha}+\mathrm{PTF}$ group. PVR in the $\mathrm{TNF}_{\alpha}$-treated group is greater than that in the $\mathrm{TNF}_{\alpha}+$ PTF group at 15 min. ${ }^{*}, p<0.01 v s$ baseline; $\dagger, p<0.02$ vs $\mathrm{TNF}_{\alpha}+$ PTF group.

mediator, either $\mathrm{TNF}_{\alpha}$ or $\mathrm{U} 46,619$, accurately reproduces all of the complex features of neonatal bacterial sepsis, especially the most clinically relevant later phases. Furthermore, the effects of recombinant $\mathrm{TNF}_{\alpha}$ on pulmonary hemodynamics are not consistent between species and perhaps between different ages in the same animal species. Guinea pigs treated with $\mathrm{TNF}_{\alpha}$ showed only modest and transient elevation in Ppa (21). Adult sheep demonstrated a marked but nonsustained pulmonary hypertensive response of rapid onset (10). In contrast to both these models, the neonatal piglet showed marked elevation in Ppa and PVR at $15 \mathrm{~min}$ and again by $2 \mathrm{~h}$ after the beginning of the $\mathrm{TNF}_{\alpha}$ infusion, a $\mathrm{TNF}_{\alpha}$ effect not completely explained by its mediation by $\mathrm{TXA}_{2}$ (6). The finding of no effect of PTF on U46,619 implies that PTF does not competitively inhibit previously formed and circulating $\mathrm{TXA}_{2}$, a finding consistent with our previous results in GBS-induced late pulmonary hypertension (11).

The mechanism of action of $\mathrm{TNF}_{\alpha}$ on the systemic and pul- monary vasculature in neonatal animals is unclear. $\mathrm{TNF}_{\alpha}$ can act both directly on endothelium and also through other vasoactive mediators (22). At least some of the acute actions of $\mathrm{TNF}_{\alpha}$ may be mediated by products of the action of phospholipase $A_{2}$ on membrane phospholipids. There is evidence that phospholipase $A_{2}$ is activated by $T N F_{\alpha}$, because both $\mathrm{TXB}_{2}$ and platelet activating factor have been shown to be released when neutrophils or monocytes are incubated with $\operatorname{TNF}_{\alpha}(22,23)$. Further, some of the signs of $\mathrm{TNF}_{\alpha}$-induced shock in rats were prevented when the $\mathrm{TNF}_{\alpha}$-exposed animals were pretreated with cyclooxygenase inhibitors (24), a finding that was not corroborated in mice when $\mathrm{TNF}_{\alpha}$ was administered with endotoxin (25). Stimulation of the endothelial monolayer by $\mathrm{TNF}_{\alpha}$ increases its adhesiveness for unstimulated neutrophils. This effect occurs because of increased expression of the adhesion molecules ICAM-1 and ELAM-1, a process requiring several hours $(26,27)$. Change in circulating cell-endothelial cell adhesiveness would be associated 


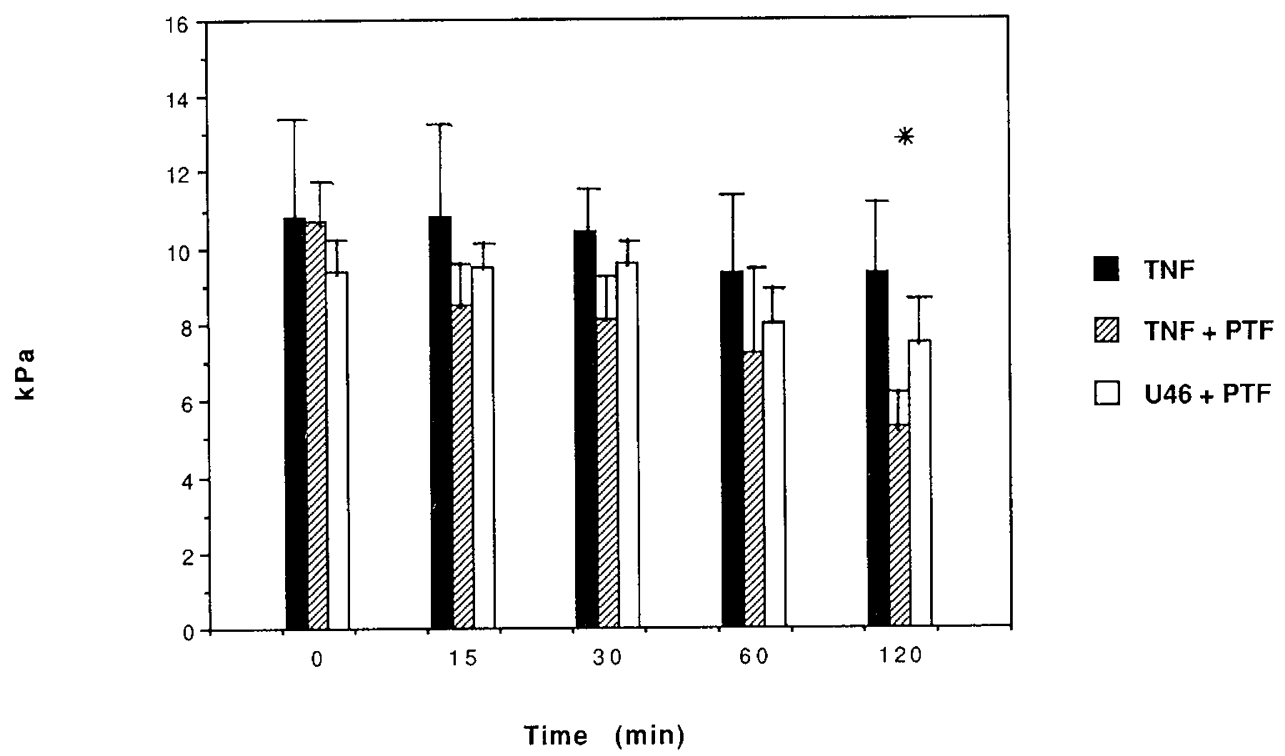

Fig. 4. Mean systemic blood pressure is plotted against experimental time points. There was no significant change from baseline in any group except the $\mathrm{TNF}_{\alpha}+\mathrm{PTF}$ group, in which mean pressure was less at $2 \mathrm{~h}$ compared to baseline. $1 \mathrm{~mm} \mathrm{Hg}=0.13 \mathrm{kPa}$. ${ }^{*}, p<0.02$.

Table 2. Blood gas data [kPa(torr)]

\begin{tabular}{|c|c|c|c|}
\hline & $\mathrm{TNF}_{\alpha}$ animals & $\begin{array}{c}\mathrm{TNF}_{\alpha}+\mathrm{PTF} \\
\text { animals }\end{array}$ & $\begin{array}{c}\mathrm{U} 46,619+\mathrm{PTF} \\
\text { animals }\end{array}$ \\
\hline \multicolumn{4}{|l|}{ Arterial $\mathrm{PO}_{2}$} \\
\hline Baseline & $11.4 \pm 1.3(86 \pm 10)$ & $11.8 \pm 0.8(89 \pm 6)$ & $10.8 \pm 1.3(81 \pm 10)$ \\
\hline $15 \mathrm{~min}$ & $10.6 \pm 1.3(80 \pm 10)$ & $11.6 \pm 0.7(87 \pm 5)$ & $10.6 \pm 1.2(80 \pm 9)$ \\
\hline $30 \mathrm{~min}$ & $10.1 \pm 1.9(76 \pm 14)$ & $11.4 \pm 1.7(86 \pm 13)$ & $10.8 \pm 1.3(81 \pm 10)$ \\
\hline $1 \mathrm{~h}$ & $10.2 \pm 1.7(77 \pm 13)$ & $11.4 \pm 1.1(86 \pm 8)$ & $10.0 \pm 0.7(75 \pm 5)$ \\
\hline $2 \mathrm{~h}$ & $10.4 \pm 2.0(78 \pm 15)$ & $10.2 \pm 1.5(77 \pm 11)$ & $10.1 \pm 1.1(76 \pm 8)$ \\
\hline \multicolumn{4}{|c|}{ Mixed venous $\mathrm{PO}_{2}$} \\
\hline Baseline & $5.7 \pm 0.7(43 \pm 5)$ & $5.6 \pm 0.5(42 \pm 4)$ & $4.8 \pm 0.5(36 \pm 4)$ \\
\hline $30 \mathrm{~min}$ & $5.3 \pm 0.3(40 \pm 2)$ & $5.2 \pm 0.7(39 \pm 5)$ & $4.7 \pm 0.4(35 \pm 3)$ \\
\hline $1 \mathrm{~h}$ & $4.9 \pm 0.5(37 \pm 4)$ & $5.0 \pm 0.7(38 \pm 5)$ & $4.5 \pm 0.7(34 \pm 5)$ \\
\hline $2 \mathrm{~h}$ & $4.3 \pm 0.8(32 \pm 6)^{*}$ & $5.3 \pm 0.7(40 \pm 5)$ & $4.8 \pm 0.7(36 \pm 5)$ \\
\hline
\end{tabular}

$* p<0.05$.

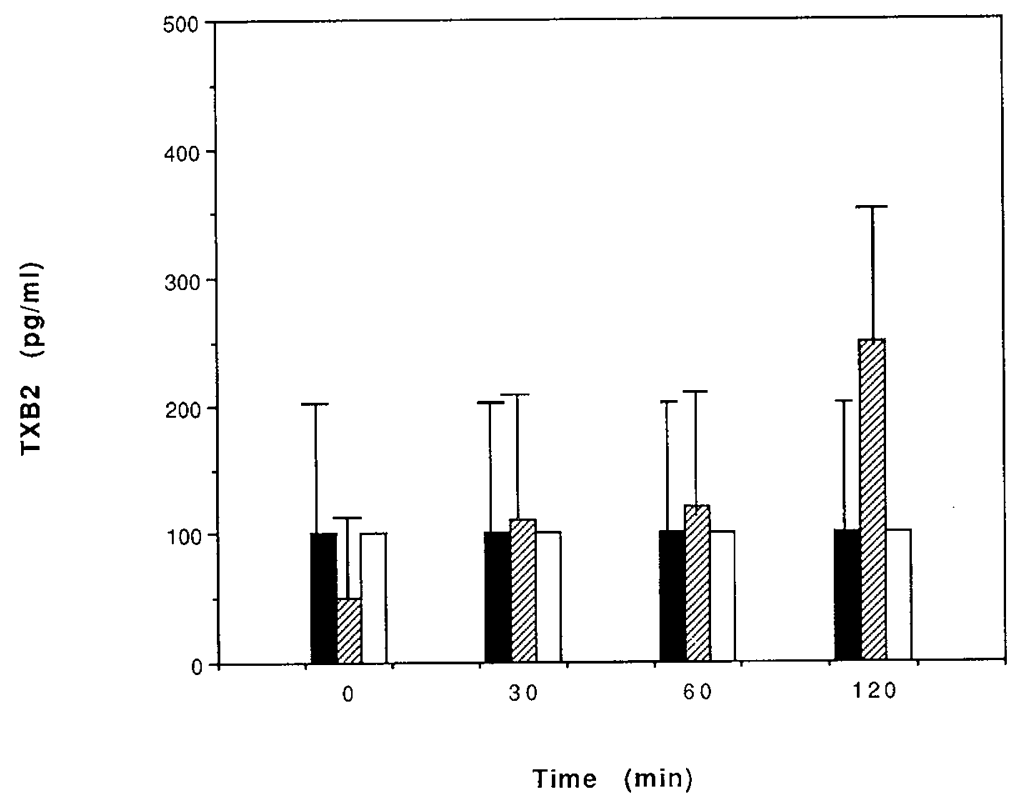

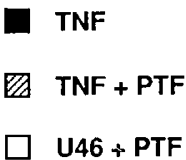

$\mathrm{U} 46+$ PTF

Fig. 5. Plasma $\mathrm{TXB}_{2}$ levels are plotted against experimental time points. No significant changes were noted $v s$ baseline at any time point. All the samples in the U46,619 + PTF group were below the sensitivity limits of the assay. 


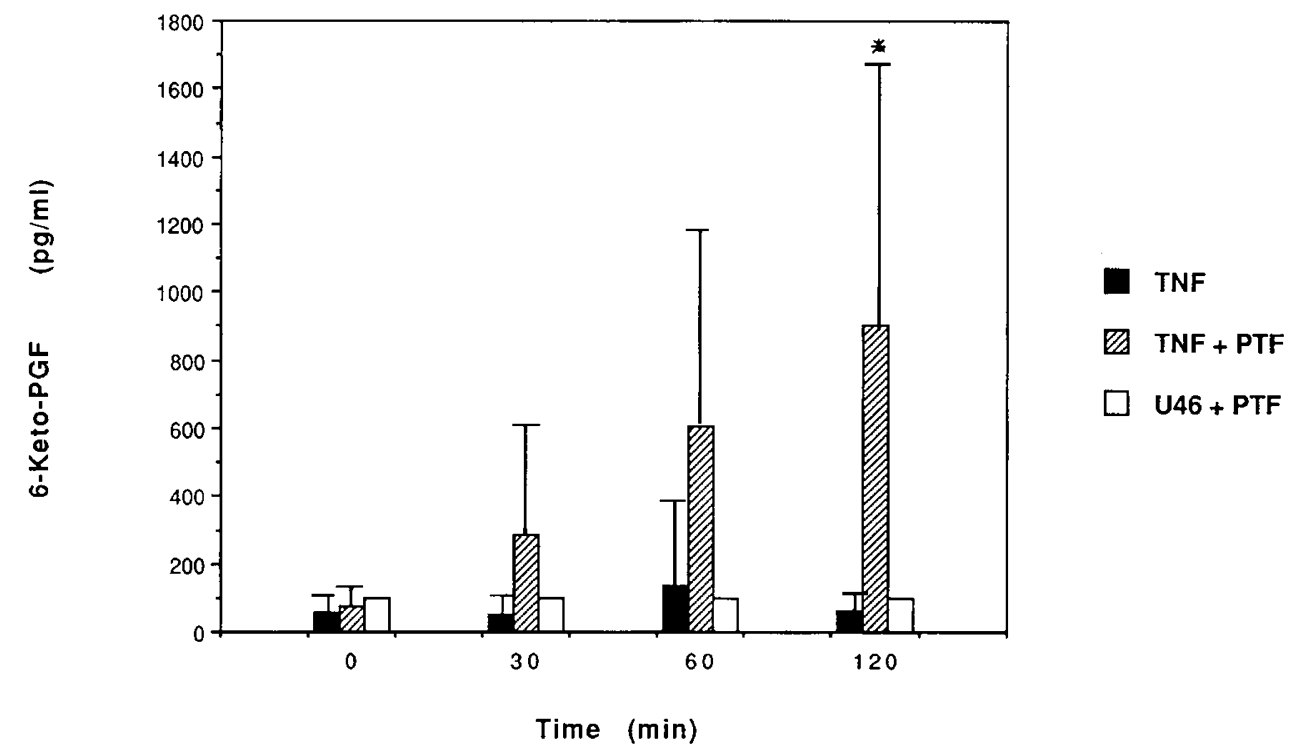

Fig. 6. Plasma 6-keto-PGF ${ }_{1 \alpha}$ levels are plotted against experimental time points. There was a significant rise in $6-$ keto-PGF $_{1 \alpha}$ in the $\mathrm{TNF}_{\alpha}+$ PTF-treated group by $2 \mathrm{~h}$. No significant change was detected in the other two groups. All the samples in the U46,619 + PTF group were below the limits of sensitivity of the test. ${ }^{*}, p<0.02$.

with endothelial conformational changes, which in turn produce a decrease in microvascular luminal area, increasing resistance to flow.

The methylxanthine derivative PTF may inhibit the action of $\mathrm{TNF}_{\alpha}$ through a variety of possible mechanisms. PTF inhibits $\mathrm{TNF}_{\alpha}$-induced changes in neutrophil adherence to endothelial cells (12) and protects in vivo against endotoxin-induced pulmonary vascular injury in both dogs (14) and guinea pigs (28). PTF reduces alveolar edema formation in rabbit lungs injured by repeated saline lavage (29). These changes may be induced by PTF by inhibiting or antagonizing the activating effect of $\mathrm{TNF}_{\alpha}$ on neutrophils. Our present results indicate that PTF transiently inhibits $\mathrm{TNF}_{\alpha}$-induced pulmonary hypertension. Based on previous work (11), we hypothesized that the elevated $\mathrm{TNF}_{\alpha}$ levels found during later phases of bacterial-product infusion contributed to pulmonary hypertension. Therefore, the present results are relevant to determining effects of the potential pulmonary vasodilator, PTF, or pulmonary hypertension caused by circulating factors that appear during later phases of sepsis. The PTF failed to maintain a sustained reduction in $\mathrm{TNF}_{\alpha}$-induced increases in PVR. Further, the PTF $+\mathrm{TNF}_{\alpha}$ animals showed the associated effect of significant systemic hypotension, which may be induced by increases in the circulating levels of $\mathrm{PGI}_{2}$, measured as its breakdown product, 6-keto-PGF ${ }_{1 \alpha}$. The increased synthesis and release of $\mathrm{PGI}_{2}$ found in the present study after combined $\mathrm{TNF}_{\alpha}+\mathrm{PTF}$ infusion may reflect a preference of neonatal endothelial cells to synthesize vasodilator substances once arachidonate metabolism is activated. $\mathrm{PGI}_{2}$ has been shown to sustain Qp to locally hypoxic regions, inhibiting the effects of local hypoxic vasoconstriction (30), an effect potentially interfering with pulmonary gas exchange. No deterioration in gas exchange was detected in the present study, probably because no significant low $\dot{\mathrm{V}}_{\mathrm{A}} / \mathrm{Q}$ areas develop with $\mathrm{TNF}_{\alpha}$ infusion at the dosage used in the current study (6). The specific site or sites of pulmonary vasodilation would determine the effect of vasodilation on gas exchange. In rabbit lungs in situ, PTF induces arterial but not venous vasodilation (31); arterial vasodilation may be less likely to produce $\dot{V}_{\mathrm{A}} / \dot{Q}$ mismatching.

Systemic hypotension developed in the PTF $+\mathrm{TNF}_{\alpha}$-treated group (Fig. 4) in spite of no significant decline in cardiac output (Fig. 2). Consistent with these results is the lack of difference in mean mixed venous $\mathrm{PO}_{2}$ at any experimental time point compared to baseline in the $\mathrm{TNF}_{\alpha}+\mathrm{PTF}$-treated group (Table 2). A modest decline in $\mathrm{PvO}_{2}$ was detected in the $\mathrm{TNF}_{\alpha}$-only animals by $2 \mathrm{~h}$. The absence of metabolic acidosis in the $\mathrm{TNF}_{\alpha}+\mathrm{PTF}$ group suggests maintenance of adequate tissue perfusion during the duration of the protocol.

The dosages of $\mathrm{TNF}_{\alpha}$ and $\mathrm{U} 46,619$ used in the present study were chosen to produce a rapid and sustained elevation in Ppa and PVR without systemic hypotension. Both dosages were derived from our previous studies with these compounds $(5,6)$ and from work with U46,619 performed by others (9). The dosage of PTF was based on data already published (28), on our own previous study (11), and on our pilot experiments that demonstrated that an infusion rate of PTF of $40 \mathrm{mg} / \mathrm{kg} / \mathrm{h}$ resulted in greater systemic hypotension than that found at the lower infusion rate.

In summary, PTF can suppress the $\mathrm{TNF}_{\alpha}$-induced increase in PVR, but not the increase induced by U46,619. However, at the dosage of PTF used, the inhibitory effect is transient, because by $2 \mathrm{~h}$ PVR is elevated to levels comparable to those found after $\mathrm{TNF}_{\alpha}$ infusion alone. This pulmonary vascular effect is accompanied by significant systemic hypotension and eicosanoid vasodilator generation. Recently, PTF has been proposed for clinical use in septic shock (32). Our findings should help establish a framework for clinical studies of PTF in pathophysiologic states in neonates presumed or shown to be associated with $\mathrm{TNF}_{\alpha}$ excess production.

\section{REFERENCES}

1. Halliday H, Hirschfield SS, Riggs T 1977 Respiratory distress syndrome: echocardiographic assessment of cardiovascular function and pulmonary vascular resistance. Pediatrics 60:444-449

2. Fox W, Gewitz M, Dinwiddie R 1977 Pulmonary hypertension in the perinatal aspiration syndrome. Pediatrics 59:205-211

3. Stenmark KR, James SL, Voelkel NV, Toews WH, Reeves JT, Murphy RC 1983 Leukotrienes C4 and D4 in neonates with hypoxemia and pulmonary hypertension. N Engl J Med 309:77-80

4. Caplan MS, Hsueh W, Sun X-M, Gidding SS, Hageman JR 1991 Circulating plasma platelet activating factor in persistent pulmonary hypertension of the newborn. Am Rev Respir Dis 142:1258-1262

5. Redding GJ, Gibson RL, Davis CB, Truog WE 1988 Effects of respiratory alkalosis on thromboxane-induced pulmonary hypertension in piglets. Pediatr Res 24:558-562

6. Truog WE, Gibson RL, Henderson WR, Redding GJ 1990 Tumor necrosis factor-induced neonatal pulmonary hypertension: effects of dazmegrel pretreatment. Pediatr Res 27:466-471

7. Sorensen GK, Redding GJ, Truog WE 1985 Mechanisms of pulmonary gas exchange abnormalities during experimental group B streptococcal infusion. Pediatr Res 19:922-926

8. Runkle B, Goldberg RN, Streitfield MM, Clark MR, Byron E, Setzer ES, 
Bancalari E 1984 Cardiovascular changes in group B streptococcal sepsis in the piglet: response to indomethacin and relationship to prostacyclin and thromboxane $\mathrm{A}_{2}$. Pediatr Res 18:874-878

9. Crowley MR, Fineman JR, Soifer SJ 1991 Effects of vasoactive drugs on thromboxane $\mathrm{A}_{2}$ mimetic-induced pulmonary hypertension in newborn lambs. Pediatr Res 29:167-172

10. Johnson JE, Meyrick B, Jesmok G, Brigham KL 1989 Human recombinant TNF $_{\alpha}$ infusion mimics endotoxemia in awake sheep. J Appl Physiol 66:14481454

11. Gibson RL, Redding GJ, Henderson WR, Truog WE 1991 Group B streptococcus induces tumor necrosis factor in neonatal piglets. Am Rev Respir Dis 143:598-604

12. Sullivan GW, Carper HT, Novick WJ, Mandell GL 1988 Inhibition of the inflammatory action of interleukin-1 and tumor necrosis factor (alpha) on neutrophil function by pentoxifylline. Infect Immunol 56:1722-1729

13. Mandell GL, Cheatham OR 1988 ARDS, neutrophils, and pentoxifylline. Am Rev Respir Dis 138:1 103-1105

14. Welsh CH, Lien D, Worthen GS, Weil JV 1988 Pentoxifylline decreases endotoxin-induced pulmonary neutrophil sequestration and extravascular protein accumulation in the dog. Am Rev Respir Dis 138:1106-1114

15. Ishizaka $A$, Wu $Z$, Stephens KE, Harada $H$, Hogue RS, O'Hanley PT, Raffin TA 1988 Attenuation of acute lung injury in septic guinea pigs by pentoxifylline. Am Rev Respir Dis 138:376-382

16. Truog WE, Gibson RL, Juul SE, Henderson WR, Redding GJ 1988 Neonatal group B streptococcal sepsis: effects of late treatment with dazmegrel. Pediatr Res 23:352-356

17. Geissler FT, Henderson WR 1988 Inability of Aflation $B_{1}$ to stimulate arachidonic acid metabolism in human polymorphonuclear and mononuclear leukocytes. Carcinogenesis 9:1135-1138

18. Geissler FT, Kuzan FB, Faustrom EM, Henderson WR 1989 Lipid mediator production by postimplantation rat embryos in vitro. Prostaglandins 38:144155

19. Redding GJ, Standaert TA, Truog WE 1985 Alterations in gas exchange associated with lobar atelectasis in young piglets. Pediatr Res 19:552-556

20. Tracey KJ, Lowry SF, Cerami A 1988 Cachectin/ TNF $_{\alpha}$ in septic shock and septic adult respiratory distress syndrome. Am Rev Respir Dis 138:13771379

21. Stephens KE, Ishizaka A, Larrick JW, Raffin TA 1988 Tumor necrosis factor causes increased pulmonary permeability and edema. Am Rev Respir Dis 137:1364-1370

22. Cammusi G, Bussolino F, Salvidio G, Baglioni C 1987 Tumor necrosis factor/ cachectin stimulates peritoneal macrophages, polymorphonuclear leukocytes and platelet-activating factor. J Exp Med 166:1390-1404

23. Difone MG, Alese E, Reale M, Bologna M, Angeletti PU, Conti P 1986 Stimulatory effect of human recombinant tumor necrosis factor on $\mathrm{TXB}_{2}$ release by polymorphonuclears and macrophages. Agents Actions 19:5-6

24. Kettelhut IC, Fiers W, Goldberg AL 1987 The toxic effects of tumor necrosis factor in vivo and their prevention by cyclooxygenase inhibitors. Proc Natl Acad Sci USA 84:4273-4277

25. Myers AK, Robey JW, Price RM 1990 Relationships between tumor necrosis factor, eicosanoids and platelet-activating factor as mediators of endotoxininduced shock in mice. Br J Pharmacol 99:499-502

26. Rothlein R, Dustin ML, Marlin SD, Springer TA 1986 An intercellular adhesion molecule (ICAM-1) distinct from LFA-1. J Immunol 137:12701275

27. Bevilacqua MP, Stengelin S, Gidmbrone MA, Seed B 1989 Endothelial leukocyte adhesion molecule 1: an inducible receptor for neutrophils related to complement regulatory proteins and lectins. Science 243:1160-1165

28. Lilly CM, Sandhu JS, Ishizaka A, Harada H, Yonemaru M, Larrick JW, Shi TX, O'Hanley PT, Raffin TA 1989 Pentoxifylline prevents tumor necrosis factor-induced lung injury. Am Rev Respir Dis 139:1361-1368

29. Seear MD, Hannam VL, Kaapa K, Raj JU, O'Brodovich HM 1990 Effect of pentoxifylline on hemodynamics, alveolar fluid reabsorption, and pulmonary edema in a model of acute lung injury. Am Rev Respir Dis 142:10831087

30. Sprague RS, Stephenson AH, Lonigro AJ 1984 Prostaglandin $I_{2}$ supports blood flow to hypoxic alveoli in anesthetized dogs. J Appl Physiol 56:1246-1251

31. Kaapa P, Hillyard R, Anderson J, Raj JU 1990 Pentoxifylline dilates pulmonary arteries but not veins in rabbits. Pediatr Res 27:357A(abstr)

32. Waxman K 1990 Pentoxifylline in septic shock. Crit Care Med 18:243-244 